\title{
Increased expression of endothelial cell nitric oxide synthase (ecNOS) in afferent and glomerular endothelial cells is involved in glomerular hyperfiltration of diabetic nephropathy
}

\author{
H. Sugimoto, K. Shikata, M. Matsuda, M. Kushiro, Y. Hayashi, K. Hiragushi, J. Wada, H. Makino \\ Department of Medicine III, Okayama University Medical School, Okayama, Japan
}

\begin{abstract}
Summary The overproduction of nitric oxide (NO) is reported in the diabetic kidney and considered to be involved in glomerular hyperfiltration. The precise mechanism of NO production in the diabetic kidney is, however, not known. In this report, we compare the localization of endothelial cell nitric oxide synthase (ecNOS) isoform expression in the kidney tissue of streptozotocin (STZ)-induced diabetic rats and 5/6 nephrectomized rats and clarify the pivotal role of ecNOS for the glomerular hyperfiltration in the early stages of diabetic nephropathy. In diabetic rats, the diameters of afferent arterioles, the glomerular volume, creatinine clearance, and urinary $\mathrm{NO}_{2} /$ $\mathrm{NO}_{3}$ were increased after the induction of diabetes. Efferent arterioles were, however, not altered. Insulin or L-NAME treatment returned the diameters of afferent arterioles, glomerular volume, creatinine clearance, and urinary $\mathrm{NO}_{2} / \mathrm{NO}_{3}$ to normal. The expression of ecNOS in afferent arterioles and glomeruli of diabetic rats increased during the early stages
\end{abstract}

of the disease, but was not altered in efferent arterioles. Treatment with either insulin or L-NAME decreased ecNOS expression in afferent arterioles and in glomeruli. In contrast, the ecNOS expression was upregulated in both afferent and efferent arterioles and in the glomeruli of 5/6 nephrectomized rats, where the dilatation of afferent and efferent arterioles and glomerular enlargement were observed. Treatment with L-NAME ameliorated the ecNOS expression and dilatation of arterioles. We conclude that enhanced NO synthesis by ecNOS in afferent arterioles and glomerular endothelial cells in response to the hyperglycaemic state could cause preferential dilatation of afferent arterioles, which ultimately induces glomerular enlargement and glomerular hyperfiltration. [Diabetologia (1998) 41: 1426-1434]

Keywords Nitric oxide (NO), endothelial cell nitric oxide synthase (ecNOS), diabetic nephropathy, afferent arterioles, glomerular hyperfiltration
Despite the progress in the therapeutic treatment of diabetes mellitus, diabetic nephropathy is one of the major complications of diabetes and the single largest

Received: 5 January 1998 and in revised form: 27 April 1998

Corresponding author: H. Sugimoto MD., Department of Medicine III, Okayama University Medical School, 2-5-1 Shikata-cho, Okayama 700 Japan

Abbreviations: NO, Nitric oxide; NOS, nitric oxide synthase; ecNOS, endothelial cell nitric oxide synthase; bNOS, brain nitric oxide synthase; iNOS, inducible nitric oxide synthase; SD, Sprague Dawley; STZ, streptozotocin; L-NAME, L-N ${ }^{\mathrm{G}}$-nitroarginine methylester HCL; FITC, fluorescein isothiocyanate; $\alpha$-SMA, $\alpha$-smooth muscle actin; OX43, surface antigen expressing on rat endothelial cells. cause of endstage renal diseases. Histologically, early diabetic nephropathy is characterized by glomerular hypertrophy and the inappropriate dilatation of afferent arterioles, which are believed to be associated with hyperfiltration and are followed by thickening of the glomerular basement membrane and accumulation of mesangial matrix $[1,2]$. The pathogenesis of glomerular hypertrophy and afferent arteriolar dilatation due to diabetes is, however, still not clear.

Nitric oxide (NO) has been identified as a pleiotropic intercellular messenger that regulates a variety of cellular functions [3] and an endothelium-derived relaxing factor that inhibits contraction of vascular smooth muscles, as well as the adhesion or aggregation of platelets [4]. Three isoforms of this enzyme have 

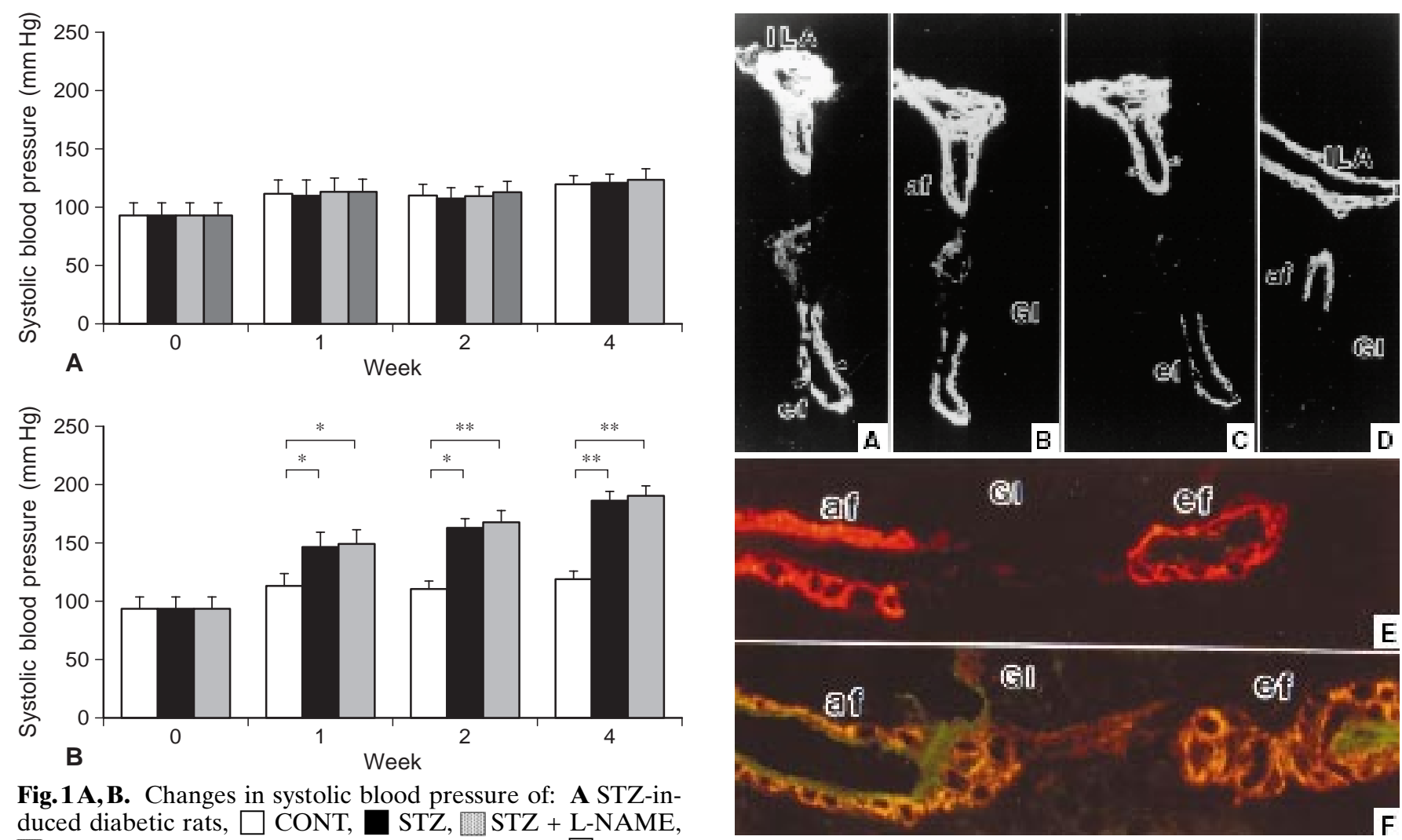

Fig.1A, B. Changes in systolic blood pressure of: A STZ-induced diabetic rats, $\square$ CONT, $\square$ STZ, $\square$ STZ + L-NAME, STZ + Insulin B 5/6 nephrectomized rats, $\square$ CONT, $5 / 6 \mathrm{Nx}$, 圆 $5 / 6 \mathrm{Nx}+\mathrm{L}-\mathrm{NAME}$

been identified, inducible nitric oxide synthase (iNOS), brain nitric oxide synthase (bNOS), and endothelial cell nitric oxide synthase (ecNOS). Evidence has accumulated to suggest the involvement of NO in the pathogenesis of diabetic nephropathy $[5,6]$. There are few studies, however, that investigate which isoform of nitric oxide synthase (NOS) is responsible for NO generation, and it is not known which cells express that NOS isoform in the diabetic kidney.

In this study, we measured the diameters of the afferent and efferent arterioles and examined the ecNOS expression in order, by immunohistochemistry, to identify the NOS-expressing cells in the renal tissues of diabetic rats. In addition, we tested the effects of an NOS inhibitor on arteriolar diameters and glomerular volumes and on ecNOS expression in diabetic rat kidneys. We also assayed ecNOS expression in the glomeruli of 5/6 nephrectomized rats, a model for glomerular hyperfiltration without hyperglycaemia. Thus, we evaluated the specific mechanism of hyperfiltration in the diabetic nephropathy.

\section{Materials and methods}

Animals. Male Sprague Dawley (SD) rats were purchased from Charles River Japan (Yokohama, Japan). Male SD rats weighing about $120 \mathrm{~g}$ (4 weeks of age) were used in experi-

Fig. 2 A-F. The representative afferent and efferent arteriole of STZ-induced diabetic rats. A-D: Serial sections of diabetic rats at 2 weeks. E-F The representative afferent, efferent arteriole, and ecNOS expression of control rats at 4 weeks (E) and STZinduced diabetic rats at 4 weeks $(\mathbf{F})$. Cryostat sections were serially incubated with anti- $\alpha$-SMA Ab, rhodamine-labelled antimouse IgG Ab, anti-ecNOS Ab, and FITC-labelled anti-mouse $\mathrm{IgG} \mathrm{Ab}$. Thus localization of ecNOS was shown by green (FITC) and $\alpha$-SMA were visualised by red (rhodamine) in $\mathbf{E}$ but by yellow (FITC + rhodamine) in F, where both FITC-labelled anti-mouse $\mathrm{Ab}$ and rhodamine-labelled anti-mouse IgG $\mathrm{Ab}$ were bonded to anti- $\alpha$-SMA Ab. ILA: interlobular artery, af: afferent arteriole, ef: efferent arteiole, Gl: glomerulus

ments 1 and 2. These rats received a standard chow and water diet. Metabolic data were measured as described previously [7]. Systolic blood pressure was measured four times a week, at the same time of day, by the indirect tail cuff method [8]. Urine samples were assayed for the stable NO metabolic end products, $\mathrm{NO}_{2}$ and $\mathrm{NO}_{3}$ with a Nitrate/Nitrite Assay Kit (Cayman Chemical, Ann Arbor, Mich., USA).

Experiment 1: STZ-Induced diabetic rats. Diabetes was induced in 30 rats by injection with streptozozotocin (STZ) [7]. Five experimental and five control rats were killed under diethylether anaesthesia at 1, 2, and 4 weeks after being injected with STZ or buffer and processed for immunohistochemical study. To study the effects of insulin treatment, $18 \mathrm{~h}$ after the injection of STZ, when all animals $(n=15)$ exhibited blood glucose concentrations above $16.7 \mathrm{mmol} / \mathrm{l}$ insulin treatment was initiated, using nearly 24 h-acting, Humalin N (Shionogi, Osaka, Japan). The dose of insulin was adjusted for individual animals in the range of 10-40 units per rat so that fasting blood glucose concentrations became $4.4-8.3 \mathrm{mmol} / \mathrm{l}$. Five insulin-treated rats were killed at 1 and 2 weeks and processed for immunohisto- 

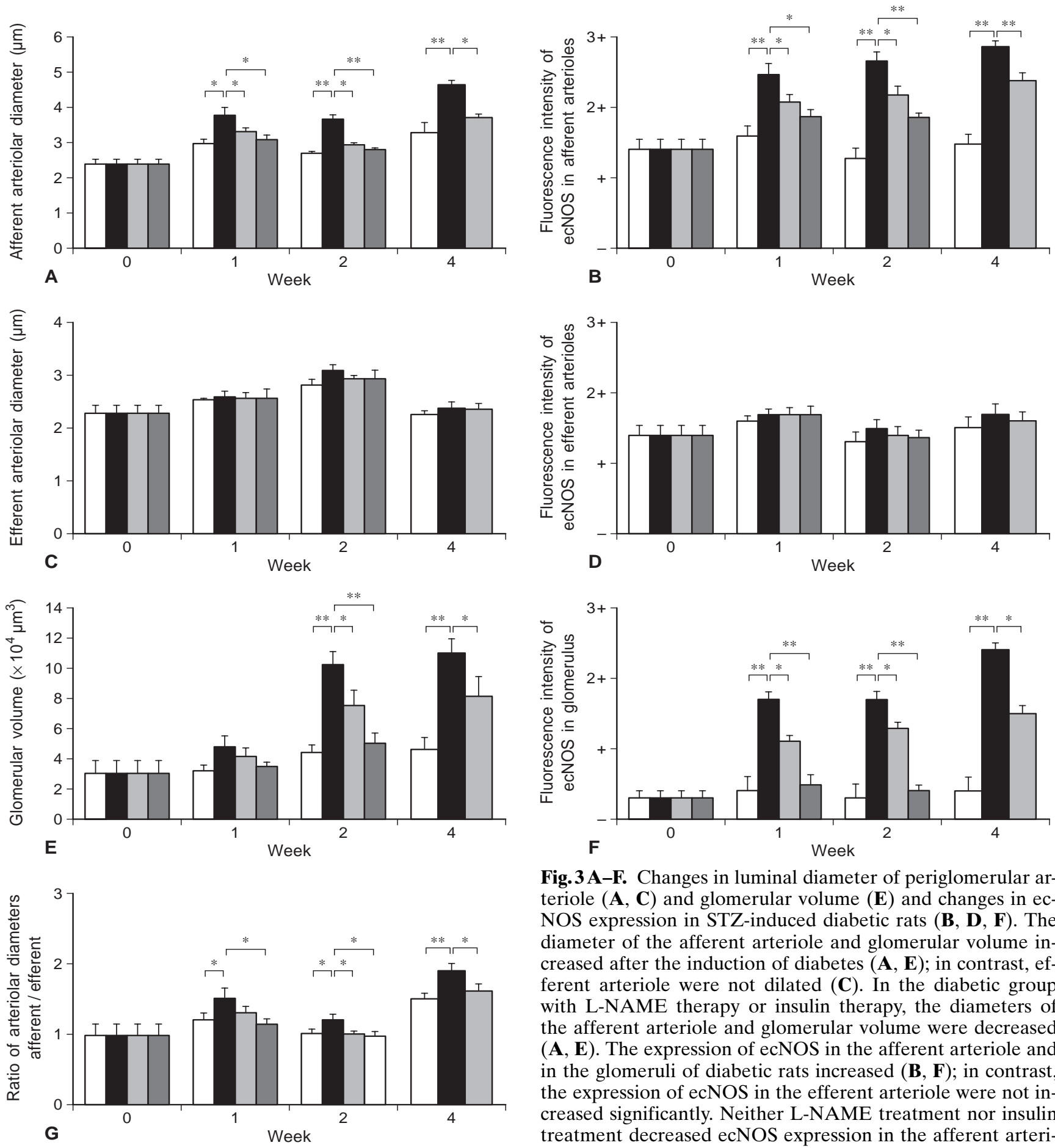

Fig. 3 A-F. Changes in luminal diameter of periglomerular arteriole $(\mathbf{A}, \mathbf{C})$ and glomerular volume $(\mathbf{E})$ and changes in ecNOS expression in STZ-induced diabetic rats $(\mathbf{B}, \mathbf{D}, \mathbf{F})$. The diameter of the afferent arteriole and glomerular volume increased after the induction of diabetes $(\mathbf{A}, \mathbf{E})$; in contrast, efferent arteriole were not dilated $(\mathbf{C})$. In the diabetic group with L-NAME therapy or insulin therapy, the diameters of the afferent arteriole and glomerular volume were decreased $(\mathbf{A}, \mathbf{E})$. The expression of ecNOS in the afferent arteriole and in the glomeruli of diabetic rats increased $(\mathbf{B}, \mathbf{F})$; in contrast, the expression of ecNOS in the efferent arteriole were not increased significantly. Neither L-NAME treatment nor insulin treatment decreased ecNOS expression in the afferent arteriole and in the glomeruli. $-=$ no detectable staining; $+=$ weak staining; $2+=$ moderate staining; $3+=$ strong staining,

chemical study. We also studied the in vivo effect of the NOS inhibitor. Diabetic rats $(n=15)$ received standard rat chow and $\mathrm{L}-\mathrm{N}^{\mathrm{G}}$-nitroarginine methyl ester $\mathrm{HCl}$ (L-NAME) (BIOMOL Research Laboratories, PA, USA) in their drinking water $(0.11 \mathrm{mmol} / \mathrm{l})$ for 4 weeks from $18 \mathrm{~h}$ after treatment with STZ. Five L-NAME-treated rats were killed at 1,2 , and 4 weeks and processed for immunohistochemical studies.

Experiment 2: 5/6 nephrectomized rats. Renal ablation was carried out in 30 male SD rats [9]. All rats were killed 1, 2, and 4 weeks later and the kidney remnants processed for immunohistochemical studies.

Histochemical staining procedure for NADPH dehydrogenase. The catalytic activity of NOS was shown by enzymatic reduction of nitro blue tetrazolium (NBT) in the presence of NAD$\mathrm{PH}$ [NADPH daiphorase (NADPH-d) reaction [10].

Antibodies. As primary antibodies, we used monoclonal antibodies (mAbs) against rat ecNOS (Transduction Laboratory, Kentucky, USA), human $\alpha$-smooth muscle cell actin ( $\alpha$-SMA) 

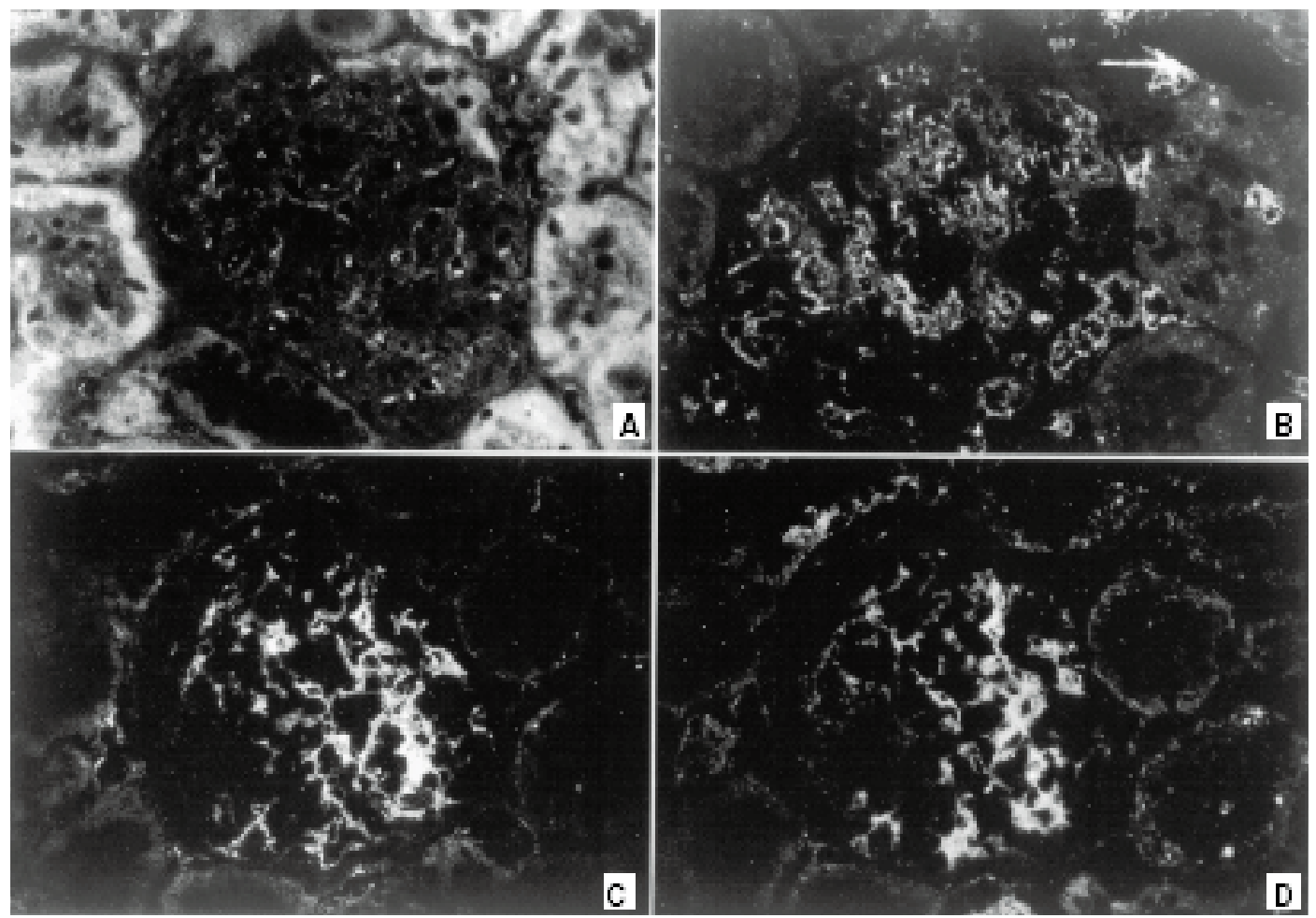

Fig. 4 A-D. Indirect immunohistochemical staining for ecNOS (A-C) in: A a control rat glomerulus at 2 weeks, magnification, $\times 200, \quad \mathbf{B}$ a STZ-induced diabetic rat glomerulus at 2 weeks, magnification, $\times 200$, C a STZ-induced diabetic rat glomerulus at 4 weeks, magnification, $\times 200$. D Indirect immunohistochemical staining for endothelial cell in a serial section of $\mathbf{C}$, magnification, $\times 200$. EcNOS-positive cells were mainly endothelial cells

(DAKO, Japan) which shows cross-reaction with rat $\alpha$-SMA, and rat endothelial cell (OX43) (BMA Biomedicals Ltd., Switzerland).

As secondary antibodies, biotinylated goat anti-mouse IgG and fluorescein isothiocyanate (FlTC)-labelled goat anti-mouse $\mathrm{IgG}$, rhodamine-labelled goat anti-mouse $\mathrm{IgG}$, neither of which lacked cross-reaction with rat IgG, were obtained from Jackson Immunoresearch Laboratories (West Grove, Pa., USA).
Indirect immunofluorescence study. Indirect immunofluorescence studies were done as described previousy $[9,11]$. To examine the localization of ecNOS-positive cells in the arterioles, cryostat sections were stained with a mAb against $\alpha$-SMA for $30 \mathrm{~min}$ at room temperature, followed by a rhodamine-labelled goat anti-mouse IgG for $30 \mathrm{~min}$ at $37^{\circ} \mathrm{C}$. Then the sections were stained with a mouse $\mathrm{mAb}$ against rat ecNOS for $60 \mathrm{~min}$ at room temperature and FlTC-labelled goat antimouse $\mathrm{IgG}$ for $30 \mathrm{~min}$ at $37^{\circ} \mathrm{C}$.

Scoring of NADPH diaphorase activity and immunostaining. The NADPH diaphorase activity and ecNOS fluorescence intensity of glomerulus and arterioles were graded semiquantita-

Fig. 5 A, B. NADPH diaphorase staining in A. a control rat at 4 weeks $(\times 200)$, B. STZ-induced diabetic rats at 4 weeks $(\times 200)$. Arrows indicate NADPH diaphorase activity
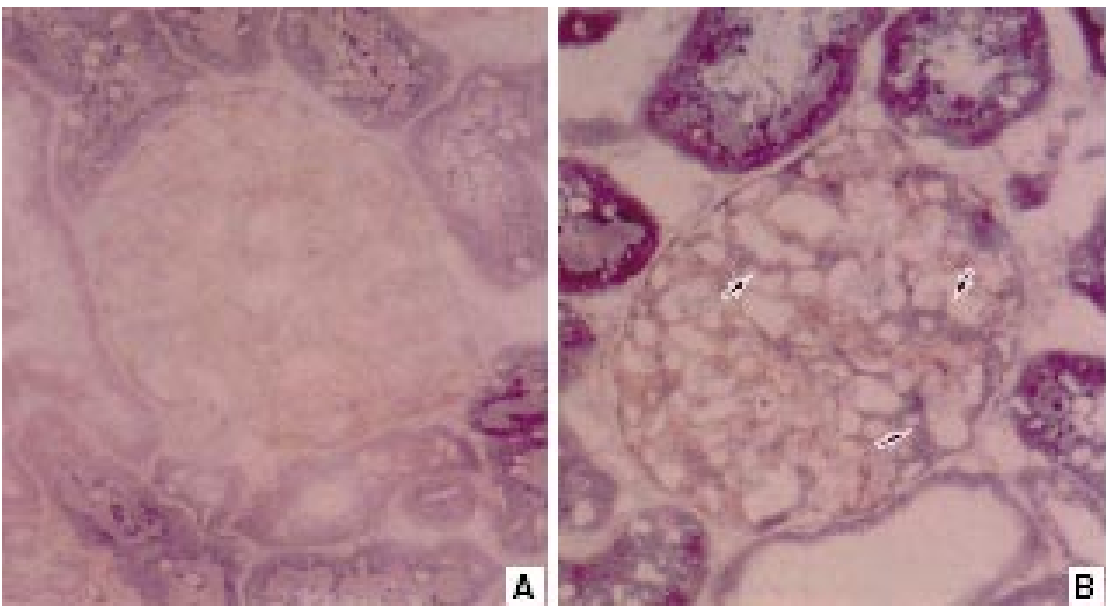
Table 1. Changes in metabolic data after induction of diabetes

\begin{tabular}{|c|c|c|c|c|}
\hline & Week 0 & Week 1 & Week 2 & Week 4 \\
\hline$(n)$ & $(5)$ & $(5)$ & (5) & (5) \\
\hline \multicolumn{5}{|l|}{ Plasma glucose $(\mathrm{mmol} / \mathrm{l})$} \\
\hline Control & $7.2 \pm 1.6$ & $7.1 \pm 0.4$ & $5.9 \pm 0.4$ & $5.1 \pm 0.6$ \\
\hline Diabetic & & $15.4 \pm 1.0^{12}$ & $16.7 \pm 0.7^{12}$ & $16.2 \pm 1.3^{1}$ \\
\hline Diabetic + Insulin & & $5.1 \pm 1.9$ & $5.8 \pm 1.3$ & nd \\
\hline Diabetic + L-NAME & & $14.8 \pm 0.8^{12}$ & $16.5 \pm 0.4^{12}$ & $16.6 \pm 0.9^{1}$ \\
\hline \multicolumn{5}{|l|}{ Fructosamine $(\mu \mathrm{mol} / \mathrm{l})$} \\
\hline Control & $126 \pm 7$ & $141 \pm 5$ & $173 \pm 6$ & $167 \pm 2$ \\
\hline Diabetic & & $186 \pm 4^{12}$ & $225 \pm 6^{12}$ & $248 \pm 5^{1}$ \\
\hline Diabetic + Insulin & & $145 \pm 14$ & $184 \pm 13$ & nd \\
\hline Diabetic + L-NAME & & $191 \pm 6^{12}$ & $236 \pm 7^{12}$ & $255 \pm 9^{1}$ \\
\hline \multicolumn{5}{|l|}{ Body weight (g) } \\
\hline Control & $105 \pm 7$ & $130 \pm 2$ & $159 \pm 3$ & $288 \pm 6$ \\
\hline Diabetic & & $126 \pm 1$ & $154 \pm 5$ & $159 \pm 4^{1}$ \\
\hline Diabetic + Insulin & & $128 \pm 1$ & $155 \pm 2$ & nd \\
\hline Diabetic + L-NAME & & $127 \pm 3$ & $152 \pm 8$ & $154 \pm 4^{1}$ \\
\hline \multicolumn{5}{|l|}{ Plasma creatinine $(\mu \mathrm{mol} / \mathrm{l})$} \\
\hline Control & $26 \pm 1$ & $28 \pm 2$ & $32 \pm 2$ & $32 \pm 4$ \\
\hline Diabetic & & $26 \pm 1$ & $35 \pm 1$ & $46 \pm 2^{1}$ \\
\hline Diabetic + Insulin & & $27 \pm 1$ & $33 \pm 2$ & nd \\
\hline Diabetic + L-NAME & & $28 \pm 3$ & $36 \pm 1$ & $46 \pm 3^{1}$ \\
\hline \multicolumn{5}{|c|}{ Urinary creatinine excretion (mg/day) } \\
\hline Control & $3.1 \pm 0.2$ & $3.5 \pm 0.1$ & $5.7 \pm 0.5$ & $10.0 \pm 0.3$ \\
\hline Diabetic & & $4.7 \pm 0.1^{12}$ & $7.4 \pm 0.4^{12}$ & $11.5 \pm 0.1^{1}$ \\
\hline Diabetic + Insulin & & $3.5 \pm 0.1$ & $6.3 \pm 0.3$ & nd \\
\hline Diabetic + L-NAME & & $4.1 \pm 0.2^{1}$ & $6.6 \pm 0.2$ & $11.0 \pm 0.3$ \\
\hline \multicolumn{5}{|c|}{ Creatinine clearance $(\mu \mathrm{l} / \mathrm{min})$} \\
\hline Control & $720 \pm 88$ & $758 \pm 16$ & $1120 \pm 60$ & $2300 \pm 129$ \\
\hline Diabetic & & $1110 \pm 40^{123}$ & $1630 \pm 50^{123}$ & $1574 \pm 44^{1}$ \\
\hline Diabetic + Insulin & & $817 \pm 39$ & $1191 \pm 38$ & nd \\
\hline Diabetic + L-NAME & & $890 \pm 42^{12}$ & $1109 \pm 41^{12}$ & $1412 \pm 34^{1}$ \\
\hline \multicolumn{5}{|c|}{ Creatinine clearance $\left(\mu \mathrm{l} \cdot \mathrm{min}^{-1} \cdot 100 \mathrm{~g}\right.$ body weight $\left.{ }^{-1}\right)$} \\
\hline Control & $688 \pm 18$ & $584 \pm 13$ & $704 \pm 35$ & $783 \pm 41$ \\
\hline Diabetic & & $881 \pm 75^{123}$ & $1025 \pm 27^{123}$ & $1001 \pm 29^{1}$ \\
\hline Diabetic + Insulin & & $640 \pm 12$ & $770 \pm 15$ & nd \\
\hline Diabetic + L-NAME & & $698 \pm 32^{1}$ & $710 \pm 22$ & $923 \pm 19^{1}$ \\
\hline
\end{tabular}

Data are means \pm SEM

nd: not done

${ }^{1} p<0.05$ vs control rats
${ }_{3}^{2} p<0.05$ vs insulin-treated diabetic rats

${ }^{3} p<0.05$ vs L-NAME-treated diabetic rats tively according to the following scale: "_" = no detectable staining, "+" = weak staining, " $2+"=$ moderate staining, $"+3 "=$ strong staining. The intensity was determined in 25 glomeruli per animal and expressed as the average intensity per glomerulus. Activity of NADPH diaphorase and immunofluorescence were evaluated for intensity and distribution by two observers independently without prior knowledge of the source of the sections.

Determination of afferent and efferent arteriolar diameters. We cut $4 \mu \mathrm{m}$-thick serial sections for the immunohistochemial studies. In each kidney specimen, 10 serial sections were prepared, stained with anti- $\alpha$-SMA Ab, and interlobular arteries, afferent, and efferent arterioles were sequentially identified [12]. In each kidney specimen, 25 afferent and efferent arterioles in arteriolar longitudinal sections were selected randomly from the superficial nephrons and evaluated. Several serial sections were observed and photographed using an Olympus fluorescent microscope (Tokyo, Japan). The thickest afferent and efferent arteriolar dimensions (luminal diameter) were then measured on photographs (X200). The diameters were measured at five points and the mean arteriolar diameter was determined by averaging all measurements by following the method of measurement described previously [13].

Glomerular size measurement. We cut 10 cryostat serial sections ( $4 \mu \mathrm{m}$-thick) and stained them by the periodic acid Schiff reaction. In each kidney specimen, the maximum diameter of 50 randomly selected glomeruli in serial sectios was measured on photographs (X150). The diameters were calculated as the mean of the longest and shortest diameters. The glomerular volume was determined from the mean glomerular diameter, $\mathrm{d}(\mathrm{G})$, using the formula: $4 \pi(\mathrm{d}(\mathrm{G}) / 2)^{3} / 3$ [7].

Statistical analysis. Values are expressed as means \pm SEM. The significance of the differences between two groups was analyzed by Wilcoxon's test. Comparisons among three groups were done by two-way analysis of variance (ANOVA) followed by Scheffe's test to evaluate the significance of the differences between any two groups. A level of $p<0.05$ was defined as statistically significant. 

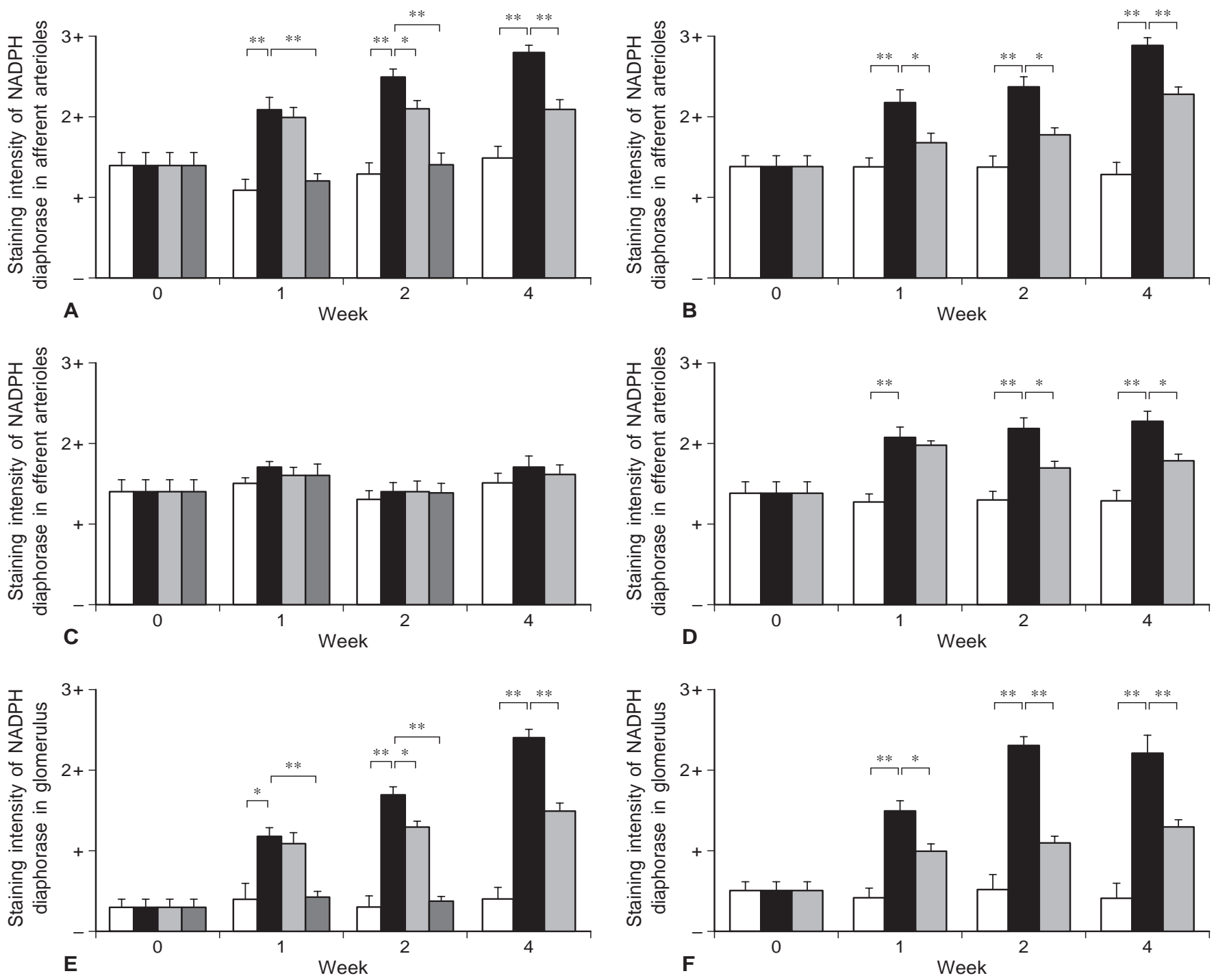

Fig.6A-F. Expression of NADPH diaphorase activity as determined by staining intensity. The staining intensity of the NADPH diaphorase in the afferent arteriole and in the glomeruli of the diabetic rats increased $(\mathbf{A}, \mathbf{E})$; in contrast, the staining intensity of the NADPH diaphorase in the efferent arteriole were not increased significantly $(\mathbf{C})$. Neither L-NAME nor insulin treatment decreased the staining intensity of the NADPH diaphorase in the afferent arteriole and in the glomeruli of diabetic rats $(\mathbf{A}, \mathbf{E})$. The staining intensity of the NAD$\mathrm{PH}$ diaphorase in both the afferent and efferent arteriole and in the glomeruli of $5 / 6$ nephrectomized rats increased, $\square$ CONT, $\square$ STZ, STZ + L-NAME, STZ + Insulin $(\mathbf{B}$, D, F). L-NAME treatment decreased the staining intensity of the NADPH diaphorase in both afferent and efferent arteriole and in the glomeruli of $5 / 6$ nephrectomized rats $(\mathbf{B}, \mathbf{D}, \mathbf{F})$. $-=$ no detectable staining; $+=$ weak staining; $2+=$ moderate staining; $3+=$ strong staining, $\square$ CONT, $5 / 0 \mathrm{Nx}, \square 5 / 0$ $\mathrm{Nx}+\mathrm{L}-\mathrm{NAME}$

\section{Results}

Experiment 1: STZ-induced diabetic rats. All diabetic rats were moderately hyperglycaemic. The serum fructosamine concentration in the diabetic group was higher than in the control rats. Creatinine clearance $\left(\mu \mathrm{l} \cdot \mathrm{min}^{-1} \cdot 100 \mathrm{~g}\right.$ body weight $\left.{ }^{-1}\right)$ in the diabetic group was higher than in the control rats from 1 to 4 weeks after the induction of diabetes (Table 1). Both the plasma glucose concentration and creatinine clearance in the insulin treated diabetic group were lower than in the untreated diabetic group. Untreated diabetic rats had higher creatinine clearance than both the control rats and L-NAME-treated diabetic rats.

We observed no significant differences in systolic blood pressure among the four groups of animals (i.e. control, diabetic, insulin-treated diabetic, and L-NAME-treated diabetic) until 2 or 4 weeks after the induction of diabetes (Fig. 1).

The representative afferent and efferent arteriole from the diabetic rats at 2 and 4 weeks after the in- 

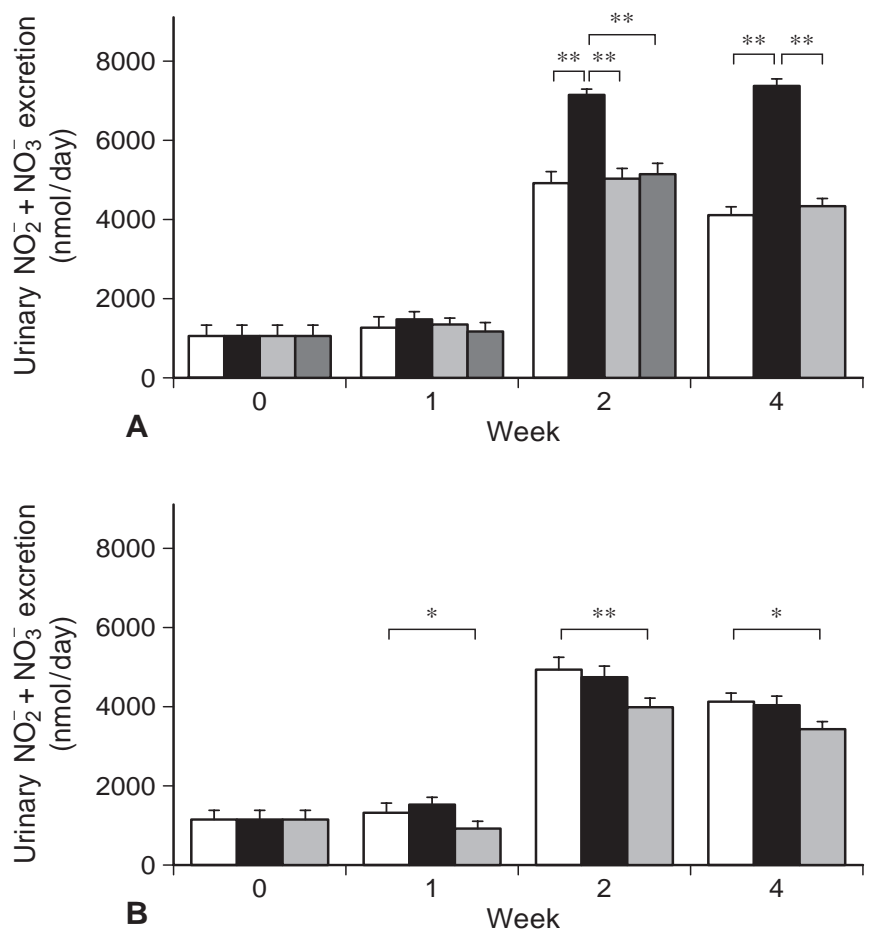

Fig. 7 A, B. Changes in urinary $\mathrm{NO}_{2}^{-} / \mathrm{NO}_{3}^{-}$excretion in $\mathbf{A}$. STZinduced diabetic rats, $\square$ CONT, $\square$ STZ, $\square \mathrm{STZ}+\mathrm{L}$ NAME, STZ + Insulin B. 5/6 nephrectomized rats, CONT, $5 / 6 \mathrm{Nx}, \quad 5 / 6 \mathrm{Nx}+\mathrm{L}-\mathrm{NAME}$

duction of diabetes is shown in Fig. 2. At 2 weeks after the induction of diabetes, the afferent arterioles showed greater dilatation in the diabetic rats than in the control, but the efferent arterioles showed no significant dilatation (Fig. 3). We found that the diameter ratio in the STZ-induced diabetic group was elevated (Fig. 3) and that in the diabetic group which received L-NAME treatment, only the afferent arterioles were constricted.

We observed a gradual increase in the glomerular volume after the induction of diabetes, and this volume was larger than in the control animals $(p<0.05)$ (Fig. 3). In the diabetic rats treated with L-NAME, however, the volume of the glomeruli was lower than in the untreated diabetic rats after 2 and 4 weeks.

The glomeruli of the control rats showed only weak staining for ecNOS (Fig. 4 A). In the afferent arterioles and in the glomeruli of STZ-induced diabetes, ecNOS fluorescence intensity was higher than in the control animals. In contrast, in the efferent arterioles of STZ-induced diabetes, ecNOS fluorescence intensity showed no significant difference from the control rats. An endothelial ecNOS staining pattern was obvious along the capillary walls 4 weeks after diabetes induction (Fig. 4C). When adjacent sections were incubated with OX43, ecNOS positive cells were mainly endothelial cells (Fig.4D). After 2 weeks of insulin treatment, ecNOS expression in the diabetic rats was similar to that in the control animals (Fig. 3). The fluorescence intensity of ecNOS in the arterioles and glomeruli of L-NAME-treated diabetic rats was less than in the untreated diabetic rats.

In the afferent arterioles and in the glomeruli of STZ-induced diabetes, staining intensity of NADPH diaphorase was higher than in the control animals, thus confirming the results of the immunohistochemical studies for ecNOS (Fig. 5 and Fig. 6).

The urinary $\mathrm{NO}_{2}^{-} / \mathrm{NO}_{3}^{-}$excretion in the diabetic group was higher than in the control group from 1 week to 4 weeks. Insulin treatment or L-NAME treatment blunted the urinary $\mathrm{NO}_{2}^{-} / \mathrm{NO}_{3}^{-}$excretion (Fig. 7).

Experiment 2:5/6 nephrectomized rats. Creatinine clearance of the 5/6 nephrectomized rats at 1 week $(784 \pm 84 \mu \mathrm{l} / \mathrm{min})($ means $\pm \mathrm{SEM})$ showed no significant difference from that of the control rats $(862 \pm$ $189 \mu \mathrm{l} / \mathrm{min})$. This result showed that the single nephron glomerular filtration rate (SNGFR) of the 5/6 nephrectomized rats was higher than that of the control rats. Creatinine clearance in L-NAME-treated $5 / 6$ nephrectomized rats $(504 \pm 78 \mu / \mathrm{min})$ as lower than in the untreated 5/6 nephrectomized rats.

In the 5/6 nephrectomized rats, both the afferent and efferent arterioles were dilated and the volume of the glomeruli gradually increased when compared with those in the control rats (Fig. 8). The diameter ratio in the nephrectomized group was increased (Fig. 8). In the 5/6 nephrectomized rats with LNAME therapy, both the afferent and efferent arterioles were constricted and the glomerular volume was decreased at 1 to 4 weeks after the renal ablation.

In the afferent and efferent arterioles and in the glomeruli of the 5/6 nephrectomized rats, the intensity of ecNOS fluorescence (Fig. 8) and the staining intensity of the NADPH diaphorase (Fig. 6) were higher than in the control group. The fluorescence intensity of ecNOS in both the afferent and efferent arterioles and in the glomeruli of the L-NAME-treated nephrectomized rats was decreased compared with untreated 5/6 nephrectomized rats.

In the nephrectomized rats, the urinary $\mathrm{NO}_{2}^{-} / \mathrm{NO}_{3}^{-}$ excretion showed no significant difference from the control animals despite the reduced renal mass (Fig.7). This result suggested that single nephron NO production of the 5/6 nephrectomized rats was higher than that of the control rats. L-NAME treatment decreased the urinary $\mathrm{NO}_{2}^{-} / \mathrm{NO}_{3}^{-}$excretion.

\section{Discussion}

Understanding the pathogenesis of abnormal renal haemodynamic responses in the diabetic state assumes importance because of the suggestion that abnormal haemodynamics could have a role in the development and progression of diabetic nephropathy, 

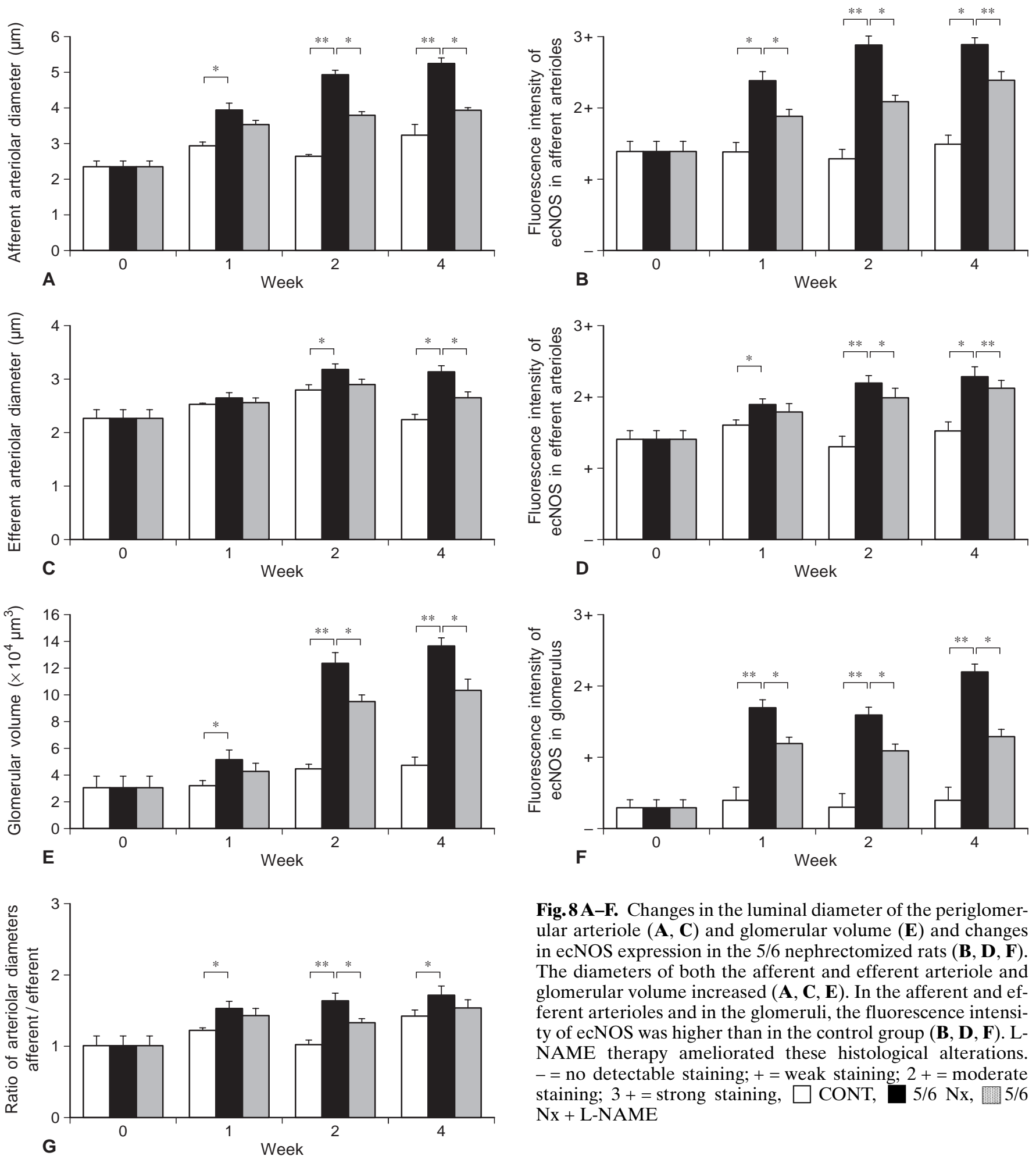

Fig. $8 \mathrm{~A}-\mathbf{F}$. Changes in the luminal diameter of the periglomerular arteriole $(\mathbf{A}, \mathbf{C})$ and glomerular volume $(\mathbf{E})$ and changes in ecNOS expression in the $5 / 6$ nephrectomized rats $(\mathbf{B}, \mathbf{D}, \mathbf{F})$. The diameters of both the afferent and efferent arteriole and glomerular volume increased $(\mathbf{A}, \mathbf{C}, \mathbf{E})$. In the afferent and efferent arterioles and in the glomeruli, the fluorescence intensity of ecNOS was higher than in the control group $(\mathbf{B}, \mathbf{D}, \mathbf{F})$. LNAME therapy ameliorated these histological alterations. $-=$ no detectable staining; $+=$ weak staining; $2+=$ moderate staining; $3+=$ strong staining, $\square$ CONT, $5 / 6 \mathrm{Nx}, \square 5 / 6$ $\mathrm{Nx}+\mathrm{L}-\mathrm{NAME}$

both in experimental animals and in patients with diabetes $[9,14]$. Furthermore, it is well-known that increased glomerular volume from the early stages of diabetes is related to the glomerular hyperfiltration. Endothelin is a potent vasoconstrictor and has been shown to induce decreased renal blood flow, decreased glomerular filtration rate and increased renal

vascular resistance [15]. Therefore, endothelin is possibly not involved in the glomerular hyperfiltration of diabetic nephropathy. Although the increased urinary excretion of $\mathrm{NO}_{2} / \mathrm{NO}_{3}$ has been reported in experimental diabetic rats $[5,6]$, which isoform of NOS is responsible for the glomerular hyperfiltration has not been well defined. 
A microvascular cast model has been used for the measurements of arterioles in an earlier study [13]. However, it is difficult to evaluate whether the measurement of arterioles by this method represents the real vascular diameters in vivo, due to the mechanical dilatation of arterioles by the infused cast. Moreover it is impossible to examine the relation between variations in arteriolar and glomerular volumes and ecNOS expression on the same sections. Thus, in the present study, using the double immunohistochemical stainings by anti- $\alpha$-smooth muscle actin ( $\alpha$-SMA) and anti-ecNOS antibody, we evaluated renal arteriolar diameters and ecNOS expression on the same sections of STZ-induced diabetic rat kidney specimens.

In our study, diabetic rats exhibited dilatation of afferent arteriolar diameters, glomerular enlargement, and functionally glomerular hyperfiltration. The increased ecNOS concentrations in the afferent arterioles were paralleled by afferent arteriolar dilatation and in the glomeruli correlated with the glomerular size of the rats in the early stages (at 1 to 4 weeks) of diabetic induction. In the rats with STZinduced diabetes, staining intensity of NADPH diaphorase was higher than in the control animals, thus supporting the results of the immunohistochemical studies for ecNOS. The increase in ecNOS expression in the diabetic rat kidney was prevented by treatment with either L-NAME or insulin. Although the mechanism of ecNOS overexpression is not clear, glycaemic control to near normal level by insulin is necessary for correction of the ecNOS expression. Urinary excretion of $\mathrm{NO}_{2}^{-} / \mathrm{NO}_{3}^{-}$was increased from 1 to 4 weeks after the induction of diabetes and was decreased by the NO synthesis inhibitor, L-NAME.

Next we compared these histological changes and ecNOS expression in diabetic rats with those in the $5 / 6$ nephrectomized rats, which is a model for glomerular hyperfiltartion without hyperglycaemia. An increased single nephron glomerular filtration rate and glomerular enlargement was also observed early after renal ablation in the 5/6 nephrectomized rats. Expression of ecNOS was increased in both the afferent and efferent arterioles and in the glomeruli of the nephrectomized group, accompanied by the dilatation of both the afferent and efferent arterioles and glomerular enlargement. In contrast, diabetic rats showed preferential ecNOS expression and dilatation in the afferent arterioles but not in the efferent arterioles. This could indicate a specific mechanism for hyperfiltration of diabetic nepohropathy and disease progression. In any event, single nephron NO production in the diabetic rats and the 5/6 nephrectomized rats was increased compared with the control rats and was decreased by the L-NAME. This finding supports our hypothesis that NO produced by ecNOS of the afferent arterioles and the glomeruli in both of these models can induce glomerular hyperfiltration and an increase in glomerular volume.

We conclude that enhanced NO synthesized by ecNOS in the afferent arterioles and glomerular endothelial cells in response to the hyperglycaemic state could induce preferential afferent arteriolar dilatation, glomerular enlargement and functionally glomerular hyperfiltration in the early stages of diabetic nephropathy.

\section{References}

1. Mauer SM, Steffes MW, Ellis EN, Sutherland DER, Brown DM, Goetz FC (1984) Structural-functional relationship in diabetic nephropathy. J Clin Invest 74: 1143-1155

2. Makino H, Yamasaki Y, Haramoto T et al. (1993) Ultrastructural changes of extracellular matrices in diabetic nephropathy revealed by high resolution scanning and immunoelectron microscopy. Lab Invest 68: 45-55

3. Nathan C (1992) Nitric oxide as a secretory product of mammalian cells. FASEB J 6: 3051-30641

4. Schmidt HHHW, Walter U (1994) NO at work. Cell 78: 919-925

5. Bank N, Aynedjian HS (1993) Role of EDRF (nitric oxide) in diabetic renal hyperfiltration. Kidney Int 43: 1306-1312

6. Komers R, Allen TJ, Cooper ME (1994) Role of endothelium-derived nitric oxide in the pathogenesis of the renal hemodynamic changes of experimental diabetes. Diabetes 43: 1190-1197

7. Sugimoto H, Shikata K, Makino H, Ota K, Ota Z (1996) Increased gene expression of insulin-like growth factor (IGFI) receptor in experimental diabetic rat glomeruli. Nephron 72: 648-653

8. Stanton HC (1971) Experimental hypertension. Methods in Pharmacology 1: 125-150

9. Sugimoto H, Shikata K, Hirata K et al. (1997) Increased expression of intercellular adhesion molecule-1 (ICAM-1) in diabetic rat glomeruli-glomerular hyperfiltration is a potential mechanism of ICAM-1 upregulation. Diabetes 46: 2075-2081

10. Bachmann S, Basse HM, Mundel P (1995) Topography of nitric oxide synthesis by localizing constitutive NO synthases in mammalian kidney. Am J Physiol 268:F885-F898

11. Makino H, Kashihara N, Suglyama H et al. (1996) Phenotypic modulation of the mesangium reflected by contractile proteins in diabetes. Diabetes 45: 488-495

12. Ljungqvist A (1964) Structure of the arteriole-glomerular units in different zones of the kidney. Micro-angiographic and histologic evidence of an extraglomerular medullary circulation. Nephron 1: 329-337

13. Kimura K, Tojo A, Hirata $Y$, Matsuoka $H$, Sugimoto $H$ (1993) Morphometric analysis of renal arterioles in subtotally nephrectomized rats. J Lab Clin Med 122: 273-283

14. Mogensen CE (1971) Kidney function and glomerular permeability to macromolecules in early juvenile diabetes. Scand J Clin Lab Invest 28: 79-90

15. King AJ, Brenner BM, Anderson S (1989) Endothelin: a potent renal and systemic vasoconstrictor peptide. Am J Physiol 256:F1051-F1058 